\title{
Neuropsychiatric manifestations of COVID-19
}

\section{When assessing altered mental status, consider COVID-19 in your differential diagnosis}

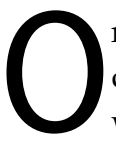
n March 11, 2020, the World Health Organization declared that coronavirus disease 2019 (COVID-19) was a pandemic. ${ }^{1}$ As of mid-May 2020, the illness had claimed more than 316,000 lives worldwide. ${ }^{2}$ The main symptoms of the respiratory illness caused by COVID-19 are fever, dry cough, and shortness of breath. However, disorders of consciousness also have been reported, especially in patients who succumb to the illness. ${ }^{3}$ In fact, approximately one-third of hospitalized COVID-19 patients experience neurologic symptoms. ${ }^{4}$ Although the most common of these symptoms are dizziness, headache, and loss of smell and taste, patients with more severe cases can experience acute cerebrovascular diseases and impaired consciousness. ${ }^{4}$ As such, psychiatrists assessing confusion should include COVID-19 in their differential diagnosis as a potential cause of altered mental status.

\section{How COVID-19 might affect the CNS}

Although primarily considered a respiratory illness, COVID-19 also may have neurotropic potential. The virus that causes COVID-19, severe acute respiratory syndromecoronavirus-2 (SARS-CoV-2), is a beta-coronavirus. Two other highly pathogenic coronaviruses-SARS-CoV-1 and Middle East respiratory syndrome-related coronavirus (MERS-CoV)—are also beta-coronaviruses, and both have been reported to invade the CNS in some patients. ${ }^{5}$ These viruses are thought to invade cells via
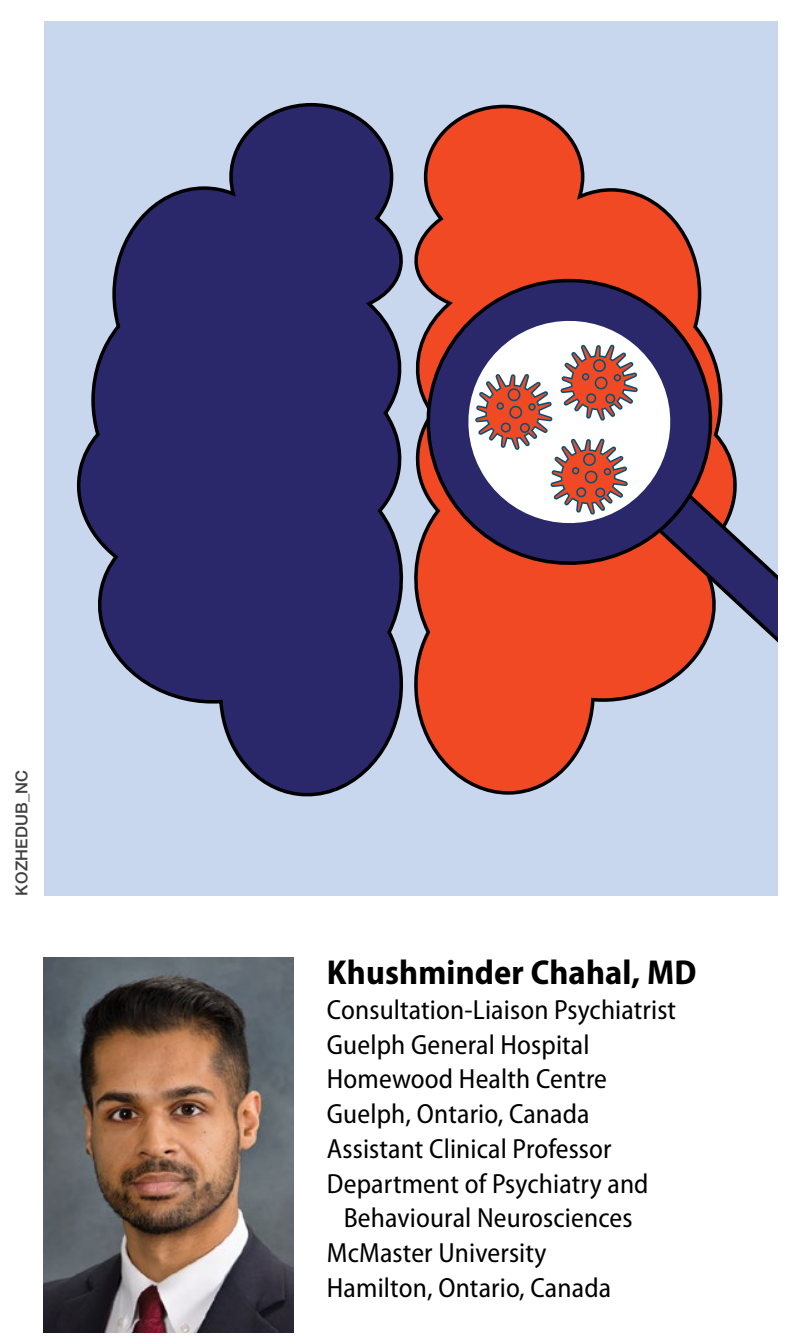

Khushminder Chahal, MD Consultation-Liaison Psychiatrist Guelph General Hospital Homewood Health Centre Guelph, Ontario, Canada Assistant Clinical Professor Department of Psychiatry and Behavioural Neurosciences McMaster University Hamilton, Ontario, Canada 


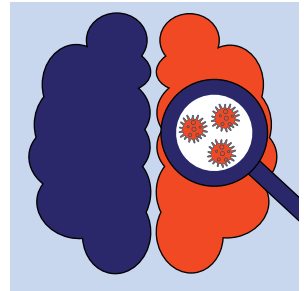

COVID-19 and altered mental status

\section{Clinical Point}

Even patients whose confusion seems to reflect a major neurocognitive disorder should be evaluated for COVID-19

Discuss this article at www.facebook.com/ MDedgePsychiatry angiotensin-converting enzyme 2 (ACE2) receptors. ${ }^{6}$ These receptors are located on the epithelial cells of the respiratory and gastrointestinal (GI) tracts, but also are expressed in certain areas of the brain. ${ }^{7}$ Transmission to the brain could occur through various routes. However, the clinical symptom of loss of smell and taste hints to possible transmission of the virus from nasal cells to the olfactory bulb via trans-synaptic transmission in olfactory neurons. ${ }^{5,8,9}$

Immune injury via systemic inflammation is another proposed mechanism for nervous system damage. ${ }^{8,9}$ This has been described as "cytokine storm syndrome" and provides support to the role of immunotherapy in COVID-19 patients. $^{10}$ Such inflammation has been long hypothesized as a contributor to psychiatric illnesses, especially neurocognitive disorders. ${ }^{11,12}$

\section{Neuropsychiatric complications of COVID-19}

Disorders of consciousness were identified early as a symptom of COVID-19. ${ }^{3}$ Subsequent studies and case reports have confirmed impaired consciousness as a possible symptom of COVID-19. ${ }^{4}$ The first case of encephalitis secondary to COVID-19 was reported by Chinese media on March 5, 2020 in Beijing, China. ${ }^{13}$ Subsequently, cases of encephalopathy secondary to COVID-19 have been reported in the United States. A 74-yearold man in Boca Raton, Florida who had recently returned from the Netherlands presented with altered mental status and was confirmed positive for COVID-19. ${ }^{14} \mathrm{~A}$ female airline worker in her late 50s who presented with altered mental status and tested positive for COVID-19 was found on imaging to have acute hemorrhagic necrotizing encephalopathy. ${ }^{15}$ There also have been cases of patients with confirmed COVID-19 who initially presented with complaints of seizures ${ }^{16}$ and GuillainBarré syndrome. ${ }^{17}$ As such, neuropsychiatric complications of COVID-19 are being increasingly recognized and are important to consider during psychiatric assessments.
Consider COVID-19 when assessing altered mental status

Psychiatrists are often consulted to assess patients with impaired consciousness, mental status changes, or confusion. Acute changes to mentation raise concern for delirium. In fact, delirium should always be ruled out when assessing new psychiatric symptoms. The astute psychiatrist is aware of the myriad of medical contributors to delirium. However, because knowledge of COVID-19 is in its infancy, it can be easy to overlook this virus as a potential contributor to delirium. Even patients whose confusion seems to be more in line with a major neurocognitive disorder should be evaluated for COVID-19, because the sudden onset of cognitive impairment may be due to hypoxia, inflammatory damage, or cerebrovascular changes secondary to infection with the virus or its respiratory complications, such as acute respiratory distress syndrome (ARDS). ${ }^{18}$

The most obvious clues to the possible presence of COVID-19 in a patient who is confused would be fever, dry cough, and shortness of breath. Because ACE2 receptors are also located in the GI tract, nausea, vomiting, and diarrhea also are possible. However, patients who are confused may be poor historians, demonstrating behavioral symptoms that might make physical assessments challenging, or simply may be pre- or asymptomatic carriers of the virus. Hence, a thorough review of the patient's history and collateral information is invaluable. A recent history of travel or contact with COVID-19-positive individuals should raise suspicion for viral infection. A patient who mentions a loss of taste or smell would also alert the psychiatrist to the possibility of COVID-19. A patient might not directly state this information, but may mention that he/she has been eating less or has not been disturbed by odors. Neuroimaging can be useful because patients with severe cases are at increased risk for acute cerebrovascular diseases. ${ }^{4}$ Also, ordering a chest CT may prove helpful because this testing is highly sensitive for COVID-19. ${ }^{19}$ If there is sufficient clinical evidence to suspect viral infection, testing for COVID-19 should be performed immediately. 
It is important to be vigilant for the possibility of COVID-19 infection in patients who present with confusion. Because the virus is highly contagious, the threshold for COVID-19 testing should be low. Viral infection in patients can manifest in ways other than classic respiratory symptoms. Psychiatrists should be aware of COVID19 's potential to invade the CNS and cause neuropsychiatric symptoms. When assessing confusion in any setting, the clinical and historical clues for COVID-19 should be kept in mind. This will allow patients with COVID-19 to be quickly diagnosed to initiate appropriate management and minimize progression of the illness. Additionally, this will allow for efficient quarantine of the patient to prevent the spread of the virus to others. As such, psychiatrists can play an important role in containing this virus and resolving the COVID-19 pandemic.

\section{References}

1. World Health Organization. Rolling updates on coronavirus disease (COVID-19). https://www.who.int/emergencies/ diseases/novel-coronavirus-2019/events-as-they-happen. Updated May 1, 2020. Accessed May 4, 2020.

2. John Hopkins University. Coronavirus resource center. World map. https://coronavirus.jhu.edu/map.html. Accessed May 4, 2020.

3. Chen $\mathrm{T}, \mathrm{Wu} \mathrm{D}, \mathrm{Chen} \mathrm{H}$, et al. Clinical characteristics of 113 deceased patients with coronavirus disease 2019: retrospective study. BMJ. 2020;368:m1091. doi: 10.1136/bmj. m1091.

4. Mao L, Wang M, Chen S, et al. Neurologic manifestations of hospitalized patients with COVID-19 in Wuhan, China: a retrospective case series study [published online February 25, 2020]. JAMA Neurol. 2020;e201127. doi: 10.1101/2020.02.22.20026500.

5. Li YC, Bai WZ, Hashikawa T. The neuroinvasive potential of SARS-CoV2 may play a role in the respiratory failure of COVID-19 patients [published online February 27, 2020]. J Med Virol. 2020;92(6). doi: 10.1002/jmv.25728.

6. Baig AM, Khaleeq A, Ali E, et al. Evidence of the COVID-19 virus targeting the CNS: tissue distribution, host-virus interaction, and proposed neurotropic mechanisms. ACS Chem Neurosci. 2020;11(7):995-998.

7. Xia H, Lazartigues E. Angiotensin-converting enzyme 2: central regulator for cardiovascular function. Curr Hypertens Rep. 2010;12(3):170-175.

\section{Related Resources}

- American Psychiatry Association. APA coronavirus resources. https://www.psychiatry.org/psychiatrists/covid-19coronavirus\#psych.

- Troyer EA, Kohn JN, Hong S. Are we facing a crashing wave of neuropsychiatric sequelae of COVID-19? Neuropsychiatric symptoms and potential immunologic mechanisms. Brain Behav Immun. 2020;S0889-1591(20)30489-X. doi: 10.1016/j.bbi.2020.04.027.

8. Steardo L, Steardo L Jr, Zorec R, et al. Neuroinfection may contribute to pathophysiology and clinical manifestations of COVID-19 [published online March 29, 2020]. Acta Physiol (Oxf). 2020;e13473. doi: 10.1111/apha.13473.

9. Wu $\mathrm{Y}, \mathrm{Xu} X, \mathrm{Chen} Z$, et al. Nervous system involvement after infection with COVID-19 and other coronaviruses [published online March 30, 2020]. Brain Behav Immun. 2020;S0889-1591(20)30357-3. doi:10.1016/j.bbi.2020.03.031.

10. Mehta P, McAuley DF, Brown M, et al; HLH Across Specialty Collaboration, UK. COVID-19: consider cytokine storm syndromes and immunosuppression. Lancet. 2020;395(10229):1033-1034.

11. McNeil JB, Hughes CG, Girard T, et al. Plasma biomarkers of inflammation, coagulation, and brain injury as predictors of delirium duration in older hospitalized patients. PLoS One 2019;14(12):e0226412. doi: 10.1371/journal.pone.0226412.

12. Heneka MT, Carson MJ, KhouryJE, etal. Neuroinflammation in Alzheimer's disease. Lancet Neurol. 2015;14(4):388-405.

13. Beijing hospital confirms nervous system infections by novel coronavirus. XINHUANET. http://www.xinhuanet. com/english/2020-03/05/c_138846529.htm. Published May 3, 2020. Accessed May 4, 2020

14. Filatov A, Sharma P, Hindi F, et al. Neurological complications of coronavirus disease (COVID-19): encephalopathy. Cureus. 2020;12(3):e7352. doi: 10.7759/ cureus.7352.

15. Poyiadji N, Shahin G, Noujaim D, et al. COVID-19associated acute hemorrhagic necrotizing encephalopathy: CT and MRI features [published online March 31, 2020]. Radiology. 2020;201187. doi: 10.1148/radiol.2020201187.

16. Karimi N, Razavi AS, Rouhani N. Frequent convulsive seizures in an adult patient with COVID-19: a case report. Iran Red Crescent Med J. 2020;22(3):e102828. doi: 10.5812/ ircmj.102828.

17. Zhao H, Shen D, Zhou H, et al. Guillain-Barré syndrome associated with SARS-CoV-2 infection: causality or coincidence? Lancet Neurol. 2020;19(5):383-384.

18. Sasannejad C, Ely EW, Lahiri S. Long-term cognitive impairment after acute respiratory distress syndrome: a review of clinical impact and pathophysiological mechanisms. Crit Care. 2019;23(1):352.

19. Fang Y, Zhang H, Xie J, et al. Sensitivity of chest CT for COVID-19: comparison to RT-PCR [published online February 19, 2020]. Radiology. 2020;200432. doi: 10.1148/ radiol.2020200432

\section{Bottom Line}

Although primarily considered a respiratory illness, coronavirus disease 2019 (COVID-19) also may have the potential to invade the CNS and cause neuropsychiatric symptoms, such as impaired consciousness, encephalitis, or a loss of taste or smell. When assessing a patient who presents with confusion, be vigilant for the possibility of COVID-19. 